\title{
Artificial Electric Field Algorithm for Optimal Power Flow Aiming Cost and Loss Minimization
}

\author{
C.Shilaja
}

\begin{abstract}
Optimal Power Flow (OPF) is a vital concern in a Electric power Network. Because of the intricacy and incoherence of strictures, the conventional formulations are not suitable to solve the problem. Hence, this study aims to resolve OPF problem consisting the objectives, by reducing the generation cost and Minimizing the Transmission power losses. So, the incessant and intermittent variables take part in the problem formulation. Artificial Electric Field Algorithm (AEFA) have been suggested to resolve the OPF problem. The simulations have been performed on IEEE -30-bus test system. The outcomes have been matched with other algorithms to exemplify the efficiency and heftiness of AEFA.
\end{abstract}

Keywords: AEFA, Cost reduction, IEEE 30 bus system, Loss minimization, $O P F$

\section{INTRODUCTION}

Carpentier introduced OPF problem in 1962 [1]. The intention of OPF problem is to estimate the best situations of an electrical network that enhance the objective functions for instance generation cost, power loss, voltage deviation, pollutant emission and no of mechanisms while nourishing power flow equations, system safety and operative bounds. Dissimilar control parameters namely real power outputs and voltages, transformer tap altering sets, and functioning rubrics for phase shifters and apparatuses have been employed to attain a best network locale according with the problem [2]. Owing to the capability of OPF problem, extensive researches have been carried out. OPF problem has been formulated and resolved by fulfilling Constraint like equality and inequality. To reduce the generating cost and Transmission power losses have been fixed as the major objectives in this study.

Recently, Artificial bee (ABC) algorithm [3], Differential Evolution algorithm (DE) [4, 5], particle swarm optimization (PSO) [6], and Multi-Hive Multi-Objective foraging Bee algorithm (MMOBA) [7] has also been utilized to resolve OPF problem. Early, the author has solved OPF problem incorporating wind generation using PSO on IEEE30 bus test system [8]. For optimizing the Economic Dispatch problem, Euclidean Affine Flower Pollination Algorithm (eFPA) and Binary FPA algorithm (BFPA) have been proposed [9]. Recently, the hybrid algorithm namely Moth Swarm- Gravitational Algorithm MSA-GSA; has been proposed to schedule wind generators on IEEE 30, IEEE 57

Revised Manuscript Received on December 05, 2019.

* Correspondence Author

C.Shilaja*, Dept of EEE, Kalasalingam Academy of Research and Education, Tamil Nadu, India. Email: shilaja.research@gmail.com and IEEE 118 buses [10]. In this study, AEFA is implemented to solve OPF problem. AEFA has been modeled to act as population, idea of charge is protracted to best solution in population by the pioneering method.

\section{PROBLEM FORMULATION}

\section{A. Reduction of cost and losses}

Reduction of cost and loss have been considered as the objectives, by the way one objective should not dominate the other.

$$
\operatorname{MinF}=\sum_{i=1}^{n g}\left(A_{i}+B_{i} P_{g i}+C_{i} P_{g i}^{2}\right)+W_{P_{\text {bas }}} \sum_{i=1}^{n}\left(G_{k}\left(V_{i}^{2}+V_{j}^{2}-2 V_{i} V_{j} \cos \delta_{i j}\right)\right)
$$

where $\mathrm{Ai}, \mathrm{Bi}$ and $\mathrm{Ci}$ are the cost coefficients of the generator bus i, Pgi is the generated active power at ith bus and $\mathrm{ng}$ is no. of generators comprising the slack bus, $\mathrm{n}$ is the branch number on the network, $\mathrm{K}$ is a branch with conductance $\mathrm{G}$ connecting the $\mathrm{i}$-th bus to the $\mathrm{j}$-th bus. Ploss is real power loss and $W_{P_{\text {loss }}}$ is the weighting factor $\left(W_{P_{\text {loss }}}=1950\right)$.

\section{B. Constraints}

Good

The equality constraints

$$
\begin{aligned}
& P_{g i}-P_{d i}=V_{i} \sum_{j=1}^{N} V_{j}\left(g_{i j} \cos \delta_{i j}+z_{i j} \sin \delta_{i j}\right) \\
& Q_{g i}-Q_{d i}=V_{i} \sum_{j=1}^{N} V_{j}\left(g_{i j} \sin \delta_{i j}+z_{i j} \cos \delta_{i j}\right)
\end{aligned}
$$

The inequality constraints

Generators bounds:

$$
\begin{aligned}
& P_{g i}^{\min } \leq P_{g i} \leq P_{g i}^{\max } \\
& Q_{g i}^{\min } \leq Q_{g i} \leq Q_{g i}^{\max } \\
& V_{g i}^{\min } \leq V_{g i} \leq V_{g i}^{\max }
\end{aligned}
$$

Tap transformer bounds:

$T^{\min } \leq T \leq T^{\max }$

Voltage magnitude for load buses bounds:

$V_{L i}^{\min } \leq V_{L i} \leq V_{L i}^{\max }$

Power flow of transmission lines bounds:

$S_{L i}^{\min } \leq S_{L i} \leq S_{L i}^{\max }$

(9)

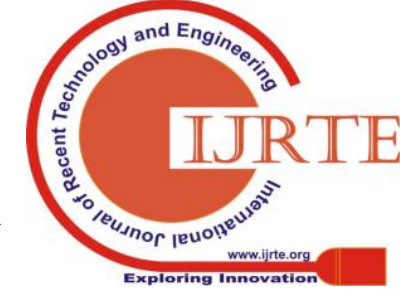




\section{Artificial Electric Field Algorithm (AEFA)}

The detailed description about AEFA has been presented in [11]. The operational flowchart of AEFA has been illustrated in Figure 1.

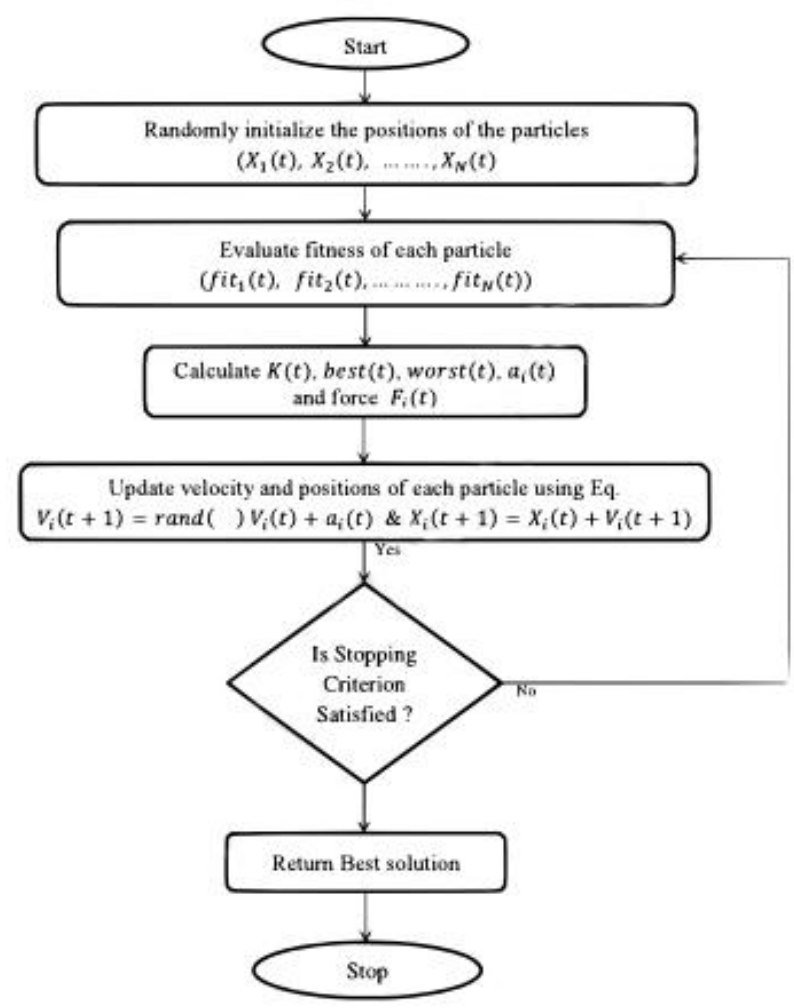

Fig. 1.Working principle of AEFA

\section{RESULTS AND DISCUSSION}

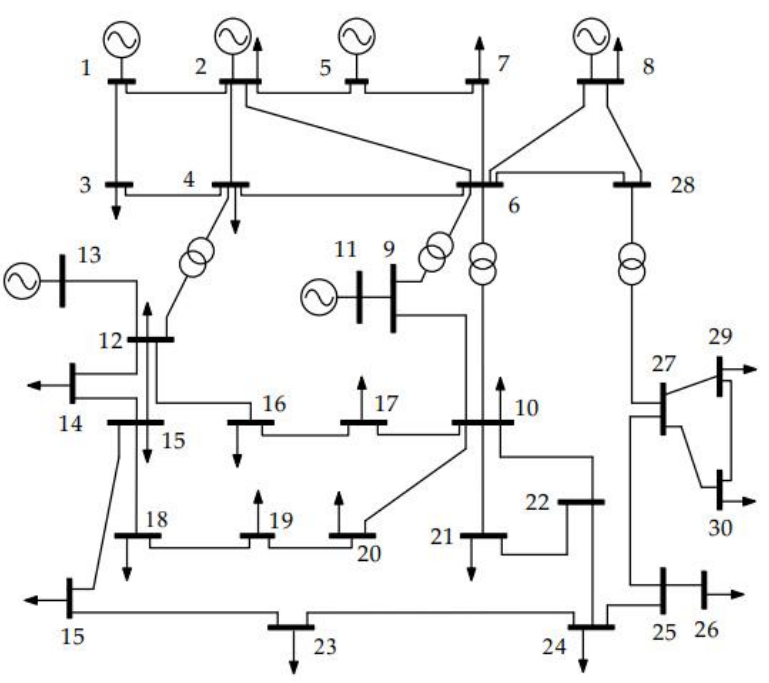

Fig. 2.Structure of IEEE- 30 bus system

The structure of IEEE - 30 bus system has been shown in Figure 2.

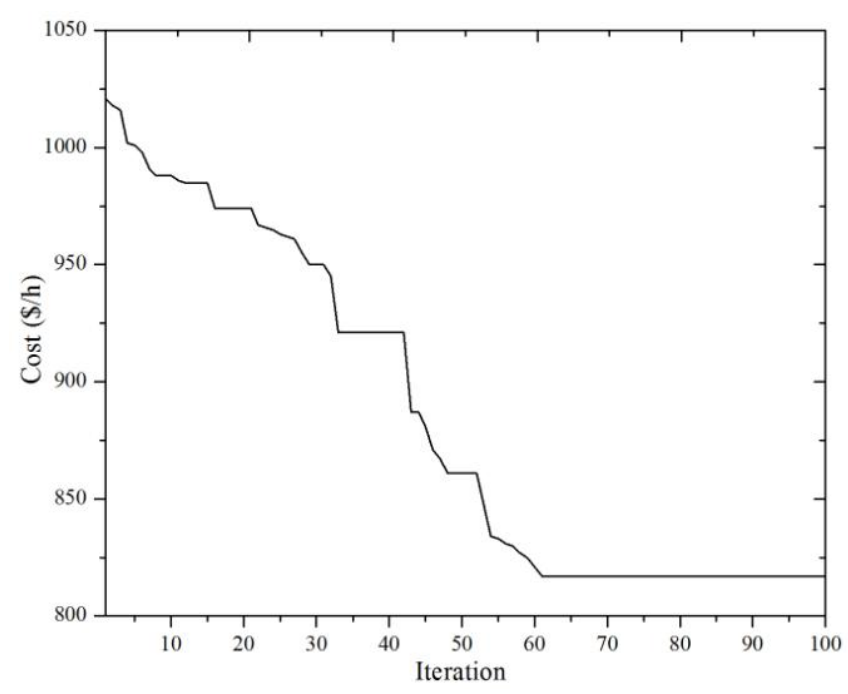

Fig. 3.Convergence characteristics of cost minimization

Table- I: Best results of OPF problem

\begin{tabular}{|l|l|l|l|}
\hline $\begin{array}{c}\text { Control } \\
\text { variables }\end{array}$ & Min & $\begin{array}{c}\text { Optimal } \\
\text { Capacity (MW) }\end{array}$ & Max \\
\hline Pg1 & 50 & 128.9488 & 200 \\
\hline Pg2 & 20 & 62.1454 & 80 \\
\hline Pg5 & 15 & 41.0154 & 50 \\
\hline Pg8 & 10 & 25.1457 & 35 \\
\hline Pg11 & 10 & 27.2404 & 30 \\
\hline Pg13 & 12 & 32.7812 & 40 \\
\hline Vg1 & 0.9 & 1.0433 & 1.1 \\
\hline Vg2 & 0.9 & 1.0078 & 1.1 \\
\hline Vg5 & 0.9 & 1.0155 & 1.1 \\
\hline Vg8 & 0.9 & 1.0852 & 1.1 \\
\hline Vg11 & 0.9 & 1.0976 & 1.1 \\
\hline Vg13 & 0.9 & 1.0948 & 1.1 \\
\hline T6-9 & 0.9 & 1.0954 & 1.1 \\
\hline T6-10 & 0.9 & 1.0578 & 1.1 \\
\hline T4-12 & 0.9 & 1.0624 & 1.1 \\
\hline T28-27 & 0.9 & 1.0278 & 1.1 \\
\hline Qc10 & 0 & 3.4597 & 5 \\
\hline Qc12 & 0 & 2.7451 & 5 \\
\hline Qc15 & 0 & 3.2687 & 5 \\
\hline Qc17 & 0 & 3.0127 & 5 \\
\hline Qc20 & 0 & 2.4782 & 5 \\
\hline Qc21 & 0 & 2.1755 & 5 \\
\hline Qc23 & 0 & 4.5478 & 5 \\
\hline Qc24 & 0 & 3.9834 & \\
\hline Qc29 & 0 & 2.1201 & \\
\hline MinCost [\$/h] & 817.0944 & \\
\hline MinP ${ }_{\text {loss }}[\mathrm{MW}]$ & 4.1782 & \\
\hline
\end{tabular}

Table- II: Comparison of results of AEFA with other optimization algorithm

\begin{tabular}{|l|l|l|}
\hline \multicolumn{1}{|c|}{ Technique } & \multicolumn{1}{c|}{ MinCost $[\mathbf{\$} / \mathbf{h}]$} & $\operatorname{Min}_{\text {loss }}[\mathbf{M W}]$ \\
\hline ABPPO [12] & 822.7693 & 5.4521 \\
\hline EGA [13] & 822.8715 & 5.6130 \\
\hline PSOGSA [14] & 822.4063 & 5.4681 \\
\hline AEFA & 817.0944 & 4.1782 \\
\hline
\end{tabular}

Using AEFA I00 trail runs have been taken out for OPF problem. The convergence curve has been shown in Figure 3. Table I provides the best result for OPF problem using AEFA. The association of results of AEFA with other optimization algorithm has been presented in Table II.

\section{CONCLUSION}

For OPF Problem the Generating Cost and power losses

Published By: 
Minimization has been taken as objectives. The enactment of AEFA has been simulated on standard IEEE 30-bus system for solving the OPF issues and the outcomes have been compared with other optimization algorithms. The comparison validated that the outcomes of AEFA provided least cost results than other algorithms. Furthermore, the convergence characteristics has been attained in less number of iterations. As a result, based on the performance, AEFA is a capable method to solve an intricate OPF problem.

\section{REFERENCES}

1. C. J, "Contribution to the ecomomic dispatch problem," Bulletin de la SocieteFrancaise Electric, vol. 3, no. 8, pp. 431-447, 1962.

2. J. A. Momoh, Electric power system applications of optimization. CRS Press, 2008.

3. M. Rezaei Adaryani and A. Karami, "Artificial bee colony algorithm for solving multi-objective optimal power flow problem," International Journal of Electrical Power \& Energy Systems, vol. 53, pp. 219-230, 2013/12/01/ 2013.

4. A. A. Abou El Ela, M. A. Abido, and S. R. Spea, "Optimal power flow using differential evolution algorithm," Electric Power Systems Research, vol. 80, no. 7, pp. 878-885, 2010/07/01/ 2010.

5. M. Varadarajan and K. S. Swarup, "Solving multi-objective optimal power flow using differential evolution," IET Generation, Transmission \& Distribution, vol. 2, no. 5, pp. 720-730, 2008.

6. M. A. Abido, "Optimal power flow using particle swarm optimization," International Journal of Electrical Power \& Energy Systems, vol. 24, no. 7, pp. 563-571, 2002/10/01/2002.

7. H. Chen, M. L. Bo, and Y. Zhu, "Multi-hive bee foraging algorithm for multi-objective optimal power flow considering the cost, loss, and emission," International Journal of Electrical Power \& Energy Systems, vol. 60, pp. 203-220, 2014/09/01/2014.

8. C. Shilaja and K. Ravi, "Optimal Power Flow Considering Intermittent Wind Power Using Particle Swarm Optimization," International journal of renewable energy research, vol. 6, no. 2, pp. 504-509, 2016.

9. C. Shilaja and K. Ravi, "Optimization of emission/economic dispatch using euclidean affine flower pollination algorithm (eFPA) and binary FPA (BFPA) in solar photo voltaic generation," Renewable Energy, vol. 107, pp. 550-566, 2017/07/01/ 2017.

10. C. Shilaja and T. Arunprasath, "Optimal power flow using Moth Swarm Algorithm with Gravitational Search Algorithm considering wind power," Future Generation Computer Systems, 2019/04/05/ 2019.

11. Anita and A. Yadav, "AEFA: Artificial electric field algorithm for global optimization," Swarm and Evolutionary Computation, vol. 48, pp. 93-108, 2019/08/01/2019.

\section{AUTHORS PROFILE}

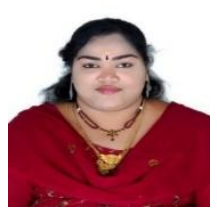

Dr.C.SHILAJA working as a Assistant Professor in EEE Department and Now currently pursuing her Post-Doctoral Fellowship from Kalasalingam University,KARE.in 2018, received her Ph.D. in Power System from VIT University Vellore in 2018, her M.E. from Sathyabama University in Power Electronics 2010 and her MBA in Human Resources from Alagappa University Karaikudi in 2007. Then her B.E. in EEE from Madras University in 2003. Her Research interests includes Optimal scheduling \& FACTS Devices. She has published 18 International journals and 4 International conferences in these areas
Published By:

Blue Eyes Intelligence Engineering 